\title{
Major axis in-plane buckling resistance of I-section beam-columns under moment gradient
}

\author{
Z. Stachura \& M.A. Giżejowski \\ Department of Concrete and Metal Structures, Warsaw University of Technology, Warsaw, Poland \\ R.B. Szczerba \\ Faculty of Civil Engineering, Warsaw University of Technology, Warsaw, Poland \\ M.D. Gajewski \\ Department of Strength of Materials and Theory of Elasticity and Plasticity, Warsaw University of \\ Technology, Warsaw, Poland
}

\begin{abstract}
The inelastic second-order resistance of I-section beam-columns under arbitrary loading cases of one-directional bending is mainly dependent upon two factors, namely the direction of bending and the contribution of the web and flanges to the section moment of inertia in the plane of bending. Based on the concept of an approximate method of the evaluation of inelastic second-order resistance of beam-columns presented by the authors elsewhere, the objective of the present study is to develop the model parameters representing functions for accounting an approximate inclusion of distributed plasticity effects of plastic zones (stress redistribution along the member length) and within the member most stressed section (stress redistribution across the most stressed section depth). The model parameters for major axis bending are assessed for narrow flange I-section beam-columns (symbol I is used for the narrow flange section identification) on the basis of results obtained from a number of FEM simulations based on an accurate shell modelling technique and using Abaqus software. The concept of equivalent geometric imperfections is applied in compliance with the so-called Eurocode's general method in order to include globally the effect of geometric and material imperfections. The resulting model parameters evaluated for I-section steelwork elements being laterally and torsionally restrained are compared with those developed elsewhere for hot-rolled wide flange HEB section members subjected to both compression and bending about the major principal axis. Additionally, results are compared with those obtained in previous studies and those of Eurocodes interaction criteria based on Methods 1 and 2. Concluding remarks with regard to the in-plane buckling resistance of double-tee section beam-columns are presented.
\end{abstract}

\section{INTRODUCTION}

When the laterally and torsionally restrained I-section beam-column, simply supported in the plane of bending is uniformly compressed and arbitrary bent about the major principal axis, its in-plane dimensionless buckling resistance curve evaluated in the plane $n_{E d}-m_{y, E d}$ is strongly dependent upon the moment gradient (where $n_{E d}=N_{E d} / N_{p l, R k}$ and $m_{y, E d}=M_{E d} / M_{y, p l . R k}$ and the other symbols sre used according to the Eurocode 3 notations, see Simoes da Silva et al. 2016). Since the axial force produces an additional moment component resulting from the $P-\delta_{z}$ effect, the member buckling resistance prediction requires a less or more precise evaluation of 
the most stressed section location along the member length. This in turn is an easy task only for the uniform bending for which the most stressed section is that at mid-length of the member. All other cases of the moment gradient need to either an estimation of the location of the most stressed section along the member length or making a rough assumption for engineering practice that the nonuniform moment case is replaced by the case of a substitute uniform moment in which the equivalent moment takes the form $M_{y, e q}=C_{m y} M_{y, \max }$ where $C_{m y}$ is the conversion factor (lower index $E d$ is dropped off in the following for the convenience of presentation).

For the reference perfect member of a linear first-order moment gradient produced by unequal support moments, the value of $M_{y, \max }$ has widely been approximated by the following relationship (see Trahair et al. 2008):

$$
\frac{M_{y, \max }}{M_{y}}=\frac{C_{m y}}{1 \frac{N}{N_{y}}} \geq 1
$$

where $N_{y}=$ lowest bifurcation (critical) force for buckling about $y-y$ axis; $\psi_{m y}=M_{y d \text {,min }}$ $I M_{y d, \text { max }}$ is the ratio of applied support moments; $C_{m y}=0.6+0.4 \psi_{m y}$ is the moment conversion factor.

Gizejowski \& Stachura (2020) postulate that for any moment gradient the maximum moment coincides with the member end section of the maximum moment, and it can be treated as a combination of symmetric and antisymmetric components, so that Equation (1) might be replaced by the following:

$$
\frac{M_{y, \max }}{M_{y}}=\frac{0.5\left(1+\psi_{m y}\right)}{1-\frac{N}{N_{y}}}+\frac{0.5\left(1-\psi_{m y}\right)}{1-\frac{N}{N_{y a}}} \geq 1
$$

where $N_{y a}=$ second-lowest bifurcation force for buckling about $y$ - $y$ axis, so that the conversion factor in Equation (1) may be approximated by:

$$
C_{m y}=0.5\left[\left(1+\psi_{m y}\right)+\left(1-\psi_{m y}\right) \frac{1-\frac{N}{N_{y}}}{1-\frac{N}{N_{y a}}}\right] \geq 1
$$

In reality, the location of the maximum moment is not at the support for any moment gradient situations but changes from the mid-section in case of the equal support moments in opposite directions to the end-section in case of the equal support moments in the same direction. For more accurate predictions, Gizejowski \& Stachura (2020) propose the deflected profile to be represented by a combination of two eigenmodes corresponding to two lowest eigenvalues detected from the bifurcation LEA analysis of a perfect column. Then, the maximum moment closed-form relationship for the section most stressed in bending is developed, more accurate than those given by Equations (1) and (2). The buckling resistance utilization ratio $B R U R$ of a straight and residual free beam-column may therefore be represented as a sum of the section resistance utilization ratio in the axial compression and the most stressed section resistance ratio in the second-order bending:

$$
B R U R=\frac{N}{N_{c, R}}+\frac{M_{y}}{M_{c y, R}} \frac{M_{y, \max }}{M_{y}} \quad 1
$$

where $N_{c, R}=$ class dependent section axial resistance; $M_{c y, R}=$ class dependent section bending resistance about $y$ - $y$ axis.

Current design codes are based on the buckling resistance models of imperfect members. Eurocode 3 (2005) introduces the Ayrton-Perry first yield column buckling model so that Equation (4) is no longer valid. It has been proposed that the resultant beam-column 
resistance utilization ratio $R U R$ can be approximated by using the maximum value of those corresponding to the class-dependent section resistance under compression and bending $C R U R$ and the class-dependent buckling resistance under compression and bending BRUR that is a simple extension of Equation (4) with $C_{m y}$ according to Equation (1) being not less than 0.4 (see Trahair et al. 2008):

$$
B R U R=\frac{N}{N_{b y, R}}+\frac{C_{m y}}{1-\frac{N}{N_{y}}} \frac{M_{y}}{M_{c y, R}} \leq 1
$$

where $N_{b y, R}=$ class-dependent buckling resistance of an imperfect column, replacing that of a perfect member $\min \left(N_{y} ; N_{c, R}\right) ; C_{m y} \geq 0.4=$ moment conversion factor according to Equation (1).

Trahair et al. (2008) suggest that the in-plane buckling resistance of beam-columns bent about $y-y$ axis may be suitably interpolated between the linear and parabolic approximations valid accordingly for single curvature bending $\left(\psi_{m y}=1\right)$ and double curvature bending $\left(\psi_{m y}=-1\right)$ :

$$
B R U R=\frac{M_{y}}{M_{c y, N, R}} \leq 1
$$

where

$$
M_{c y, N, R}=M_{c y, R}\left\{\left[1-\left(\frac{1-\psi_{m y}}{2}\right)^{3}\right]\left(1-\frac{N}{N_{b y, R}}\right)+1.18\left(\frac{1-\psi_{m y}}{2}\right)^{3} \sqrt{1-\frac{N}{N_{y}}}\right\} \leq M_{c y, R}
$$

Eurocode 3 (2005) introduces the interpolation equations being distinctively different from those of Equations (5) and (6). Moreover, they include the fact that different double-tee sections have different technological imperfections affecting the buckling response. The buckling resistance of rolled double-tee section columns is dependent upon the ratio of the section depth and flange width as well as upon the flange thickness while the buckling resistance of their welded counterparts is dependent mainly upon the flange thickness.

Many recent investigations refer to interpolation equations adopted in current design codes in order to propose alternative analytical-numerical formulations that allow for even more reliable reproduction of in-plane and out-of-plane buckling resistances of real (imperfect) beam-columns. Kucukler et al. (2015) developed a direct design method, the so-called stiffness reduction method, that takes into account the detrimental influence of imperfections and effect of distributed plasticity on the buckling resistance of beam-columns. Authors of this paper refined the so-called General Method of Eurocode 3 (2005) in their study of Gizejowski et al. (2019b). The study was referred to wide flange double-tee beam-columns of the size ratio $h / b \leq 1.2$ (symbol $\mathrm{H}$ was used for such section identification). For the buckling resistance of $\mathrm{H}$-section beam-columns, the degrading effect of imperfections, as well as the effect of inelastic stress redistributions across the sections and the member length were suitably included in the proposed formulation. For evaluating the in-plane buckling resistance of $\mathrm{H}$-section beamcolumns, the amplified second-order formulation developed introduced the model parameters which were calibrated (Gizejowski et al. 2019a). Since the developed approach would rather be considered as general but model parameters were calibrated for $\mathrm{H}$-section beam-columns, it needs to be verified when postulated to be used in the buckling resistance prediction of I-section beam-columns for which $h / b>1.2$. This study is entirely devoted to this issue.

Firstly, a brief description of the proposed model is presented. Next, the model parameters are calibrated for I-section beam-columns subjected to unequal end moments. The verification exercise is carried out by using FEM results from a numerical shell model built up within the framework of ABAQUS software. Resultant calibrated model parameters for I-section beam-columns are compared with those developed earlier for $\mathrm{H}$-section beam-columns. Finally, the results from the 
proposed model and calibrated model parameters were compared with those obtained with the use of interpolation formulas adopted in Eurocode 3 (2005) in which the interaction factors were evaluated according to Methods 1 and 2 according to respectively Annexes A and B of that code. Conclusions with regard to engineering practice are formulated.

\section{ANALYTICAL MODEL FOR IN-PLANE BUCKLING RESISTANCE}

\subsection{Brief description of proposed model}

The base model was studied and its details were presented and discussed in the authors original paper of Gizejowski et al. (2019a). In the following, the proposed model based on a linear combination of elementary resistance utilisation ratios is called the refined analytical formulation (RAF).

\subsection{Finite element simulations and calibration of I-section beam-column model parameters}

A representative narrow flange section of IPE 180 made of steel grade S235 is used. Beamcolumns of the comparative slenderness ratio being the same as those used for $\mathrm{H}$-section members of HEB 300 in Gizejowski et al. (2019a) are used, namely 0.5, 1.0, 1.5. The method of equivalent geometric imperfection is used for numerical simulations. The imperfection amplitude was calculated according to Eurocode 3 (2005) using the plastic properties of the section. For the I-section used in simulations, the Eurocode's buckling curve " $a$ " is relevant, therefore the imperfection factor of $\alpha_{y}=0.21$ has to be used. The results of the finite element method simulations (FEM) were obtained using ABAQUS software with shell modelling techniques. The constitutive steel model was piece-wise-linear elastic-plastic with isotropic hardening. More details can be found in Gizejowski et al. (2019a).

\subsection{Comparison of model parameters for I- and H-section beam-column}

In Table 1, the values of calibrated model parameters are summarized for I- and H-section beam-columns (for H-section members, see Gizejowski et al. 2019a).

Figure 1 shows the comparison, in dimensionless coordinates, of the in-plane resistance curves of I-section and $\mathrm{H}$-section beam-columns under unequal end moments and two extreme cases of moment gradient ratios, namely $\psi_{m y}=1$ and -1 and three slenderness ratios.

From the comparison of results presented in Figure 1 one can observe that zones of the stable behaviour of $\mathrm{I}$ - and $\mathrm{H}$-section beam-columns are not identical. The zone bounded by the ultimate strength curves for I-section beam-columns is greater than that for $\mathrm{H}$-section of corresponding slenderness ratios. It is visible good consistency between RAF and FEM results for members of IPE 180 cross-section, as well. Comparison of the in-plane resistance results of RAF and FEM for members of HEB 300 were presented in Gizejowski et al. (2019a).

Table 1. Comparison of model parameters for I- and H-section beam-columns.

\begin{tabular}{llllll}
\hline & \multicolumn{2}{l}{ Section depth } & & \multicolumn{2}{l}{ Member length } \\
\cline { 2 - 3 } \cline { 6 - 7 } Redistribution & $c_{c y}$ & & & $c_{b y}$ & $\gamma$ \\
\hline H-section & 3.75 & 2.0 & & 3.75 & 2.0 \\
I-section & 3.75 & 3.0 & & 11.25 & 3.0 \\
\hline
\end{tabular}


a)

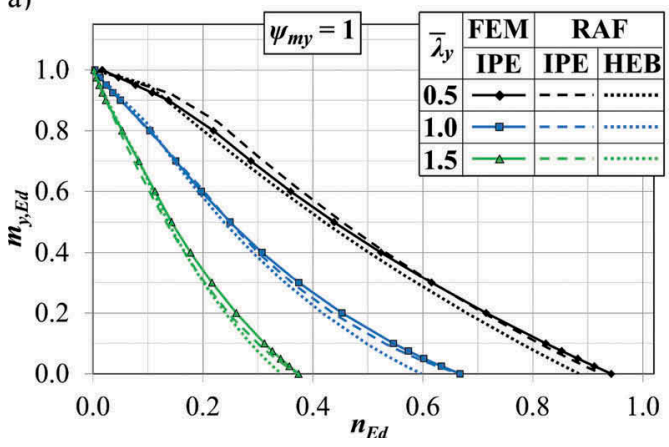

b)

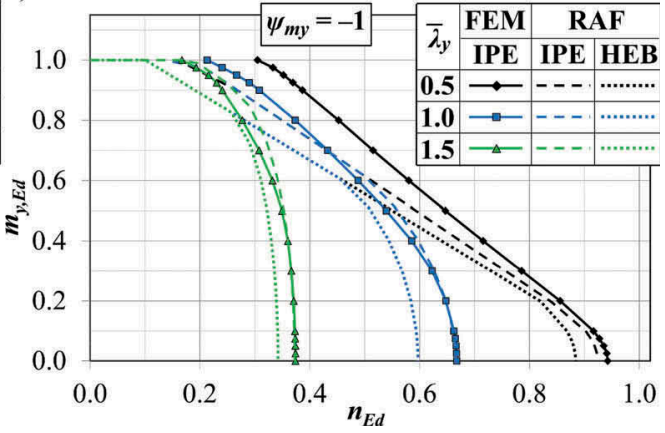

Figure 1. Comparison of ultimate strength curves for I- and H-section beam-columns: a) $\psi_{m y}=1$; b) $\psi_{m y}=-1$.

\section{COMPARISON USING EUROCODE'S INTERPOLATION RELATIONSHIP}

\subsection{Brief description of Eurocode 3 interpolation relationship approach}

Eurocode 3 (2005) provides a set of resistance interpolation functions for the section resistance and the member buckling resistance as well as the interaction factors of the latter are obtained with the use of Method 1 (Annex A, background given by Boissonnade et al. 2004) or Method 2 (Annex B, background given by Greiner \& Lindner 2006).

\subsection{Presentation of results}

Figure 2 shows the comparison, in dimensionless coordinates, of the in-plane resistance curves of I-section beam-columns under unequal end moments and two moment gradient ratios, namely $\psi_{m y}=1$ (symmetrical bending) and -1 (antisymmetrical bending) and three slenderness ratios. Results from the authors' analytical model with the model parameters of the present study (marked as RAF) are compared with those from the Eurocode's interpolation relationships and interaction factors according to Method 1 (marked as EN-M1).

From the comparison of results presented in Figure 2 one can observe that curves of present study, verified positively with the use of FEM simulations (see Figure 1), are generally placed above those based on the Eurocode 3 (2005) and member interpolation equations with the use of interaction factors according to Method 1 . In case of the uniform bending moment $\left(\psi_{m y}=1\right)$

a)

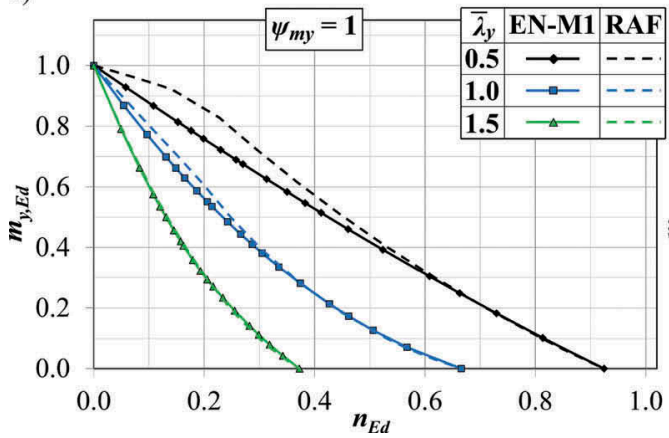

b)

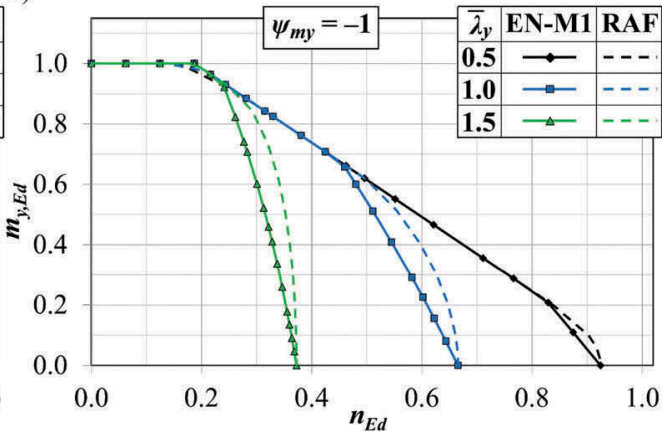

Figure 2. Comparison of ultimate strength curves of present study and Method 1 Eurocode's interpolation relationships: a) $\psi_{m y}=1$; b) $\psi_{m y}=-1$. 
a)

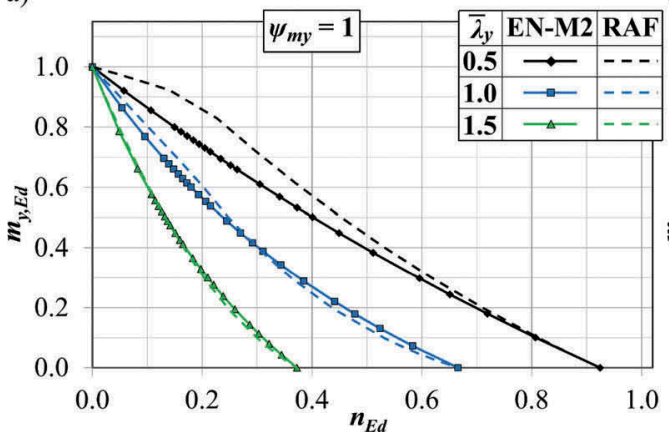

b)

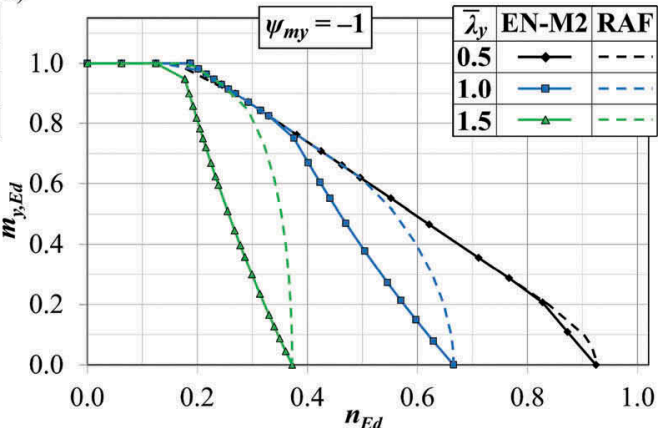

Figure 3. Comparison of ultimate strength curves of present study and Method 2 Eurocode's interpolation relationships: a) $\psi_{m y}=1$; b) $\psi_{m y}=-1$.

and the member slenderness ratio equals to 1.0 and 1.5 both analytical formulations are close to each other. Good consistency between considered methods is for the antisymmetric moment diagram $\left(\psi_{m y}=-1\right)$ and the member slenderness ratio 0.5 , as well. The difference is increasing with decreasing value of the moment gradient ratio $\psi_{m y}$ where an antisymmetric loading component is more important.

Figure 3 shows the comparison of the RAF developed herein for I-section beam-columns and the results of the Eurocode's interpolation relationships and interaction factors according to Method 2 (marked as EN-M2). Results are presented for the same moment gradient ratios $\psi_{m y}$ and slenderness ratios as in Figure 2. Observing the results of the conducted comparison, one can conclude that curves of the present study are practically above those calculated from Eurocode's interaction equations and interaction factors according to Method 2, especially for antisymmetrical bending moment. In case of the uniform bending moment $\left(\psi_{m y}=1\right)$ and the member slenderness ratio equals to 1.0 and 1.5 both analytical formulations are close to each other. The same observation is for the antisymmetric moment diagram $\left(\psi_{m y}=-1\right)$ and the member slenderness ratio 0.5 . The highest differences between all methods presented in Figures 2 and 3 are for $\psi_{m y}=-1$ and the member slenderness ratio 1.0 and 1.5 .

\section{CONCLUDING REMARKS}

In this paper, based on the concept of an approximate method of the evaluation of inelastic second-order resistance of beam-columns presented by Gizejowski et al. (2019a), the model parameters for narrow flange I-section beam-columns were developed. Investigations concerned the functions for accounting an approximate inclusion of distributed plasticity effects of plastic zones (stress redistribution along the member length) and within the member most stressed section (stress redistribution across the most stressed section depth).

The results presented in Figures 2 and 3 indicate that the analytical model developed in Gizejowski et al. (2019a) for the in-plane buckling resistance is considerably less conservative than that of Eurocode's Method 1 and Method 2. The comparison of results in Figures 2 and 3 clearly supports the conclusion that the concept of the so-called equivalent uniform moment factor used in Eurocode 3 (2005) results in significantly more conservative results, specifically for the antisymmetrical loading component $\left(\psi_{m y}=-1\right)$ and when Eurocode's Method 2 is used. The advantage of the proposed formulation is that there is no need for the introduction of any equivalent moment factor. The developed model has a simple physical interpretation and is based on a linear combination of elementary resistance utilisation ratios. In addition, the proposed analytical model has only one design condition instead of 
two required by Eurocode 3 (2005), where the cross-section capacity and the overall stability must be checked separately.

The verification of the results presented in subsection 2.3 and Gizejowski et al. (2019a) indicates that the proposed analytical model of the in-plane buckling resistance represents the behaviour of imperfect I- and H-section beam-columns with sufficient accuracy for practical applications for any value of the moment gradient ratio or member slenderness ratio.

\section{REFERENCES}

Boissonnade, N., Jaspart, J.-P., Muzeau, J.-P. \& Villette, M. 2004. New interaction formulae for beam-columns in Eurocode 3: The French-Belgian approach. Journal of Constructional Steel Research 60: 421-431.

Eurocode 3 2005. Design of steel structures, Part 1-1: General rules and rules for buildings. Brussels: European Committee for Standrization.

Gizejowski, M.A., Stachura, Z., Szczerba, R.B. \& Gajewski, M.D. 2019a. Buckling resistance of steel I-section beam-columns: in-plane buckling resistance. Journal of Constructional Steel Research 157: $347-358$.

Gizejowski, M.A., Stachura, Z., Szczerba, R.B. \& Gajewski, M.D. 2019b. Out-of-plane buckling resistance of rolled stel H-section beam-columns under unequal end moments. Journal of Constructional Steel Research 160: 153-168.

Gizejowski, M.A. \& Stachura, Z. 2020. On evaluation of maximum second order elastic moment of steel elements under compression and bending being produced by moment applied at supports. Inżynieria $i$ Budownictwo 76(4-5): 228-231 [in Polish].

Greiner, R. \& Lindner, J. 2006. Interaction formulae for members subjected to bending and axial compression in Eurocode 3: The Method 2 approach. Journal of Constructional Steel Research 62: 757-770.

Kucukler, M., Gardner, L. \& Macorini, L. 2015. Flexural-torsional buckling assessment of steel beam-columns through a stiffness reduction method. Engineering Structures 101: 662-676.

Simoes da Silva, L., Simoes, R. \& Gervasio, H. 2016. Design of steel structures. Eurocode 3: Design of steel structures, part 1-1 - General rules and rules for buildings (Second edition). ECCS Eurocode Design Manuals. Berlin: Wilhelm Ernst \& Son.

Trahair, N.S., Bradford, M.A., Nethercot, D.A. \& Gardner, L. 2008. The behaviour and design of steel structures to EC3 (Fourth edition). Abington: Taylor \& Francis. 